\title{
Gender difference in the change of adolescents' mental health and subjective wellbeing trajectories
}

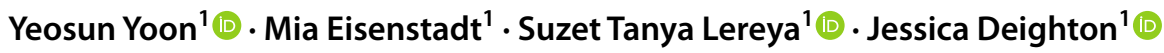

Received: 15 June 2021 / Accepted: 10 February 2022

(c) The Author(s), under exclusive licence to Springer-Verlag GmbH Germany 2022

\begin{abstract}
Gender differences in adolescents' mental health problems have been extensively reported. Yet, there is limited research in exploring longitudinal trends in mental health and wellbeing between boys and girls. This study investigated any emerging developmental trends of gender differences in mental health problems and subjective wellbeing for young people from early to mid-adolescence in England. A longitudinal group of 8612 young people's mental health and subjective wellbeing trajectories were investigated between the period of ages 11/12 and 13/14. Mental health difficulties and subjective wellbeing were measured using the child self-report Strengths and Difficulties Questionnaire (SDQ) and Short Warwick and Edinburgh Wellbeing Scale (SWEMWBS), respectively. Any gender difference in the change of adolescents' mental health and subjective wellbeing over 3 year period were estimated using multi-level regression while accounting for various sociodemographic and resilience factors. Young people are at increased risk of mental health problems between the ages of 11 and 14, particularly girls. The overall difficulty levels reported by girls were significantly higher than boys across a range of mental health problems and subjective wellbeing. These developmental trends persisted after controlling for a broad range of potential confounders. Young people has shown clear signs of mental distress as they get older. This escalation was particularly evident among girls. Distress can come at the time of significant physical, emotional, and social changes in an adolescents' life, and can be heightened during secondary school transition. This evidence highlights the importance of early intervention to reduce risk of distress.
\end{abstract}

Keywords Mental health and wellbeing $\cdot$ Children and young people $\cdot$ Longitudinal analysis

\section{Introduction}

\section{Background/rationale}

Recent research estimates that 1 in 8 children and young people experience mental health problems in England and its record went up to 1 in 6 during the COVID-19 pandemic [34, 35]. Evidence also indicates that there might be higher rates

Yeosun Yoon

yeosun.yoon@annafreud.org

Mia Eisenstadt

mia.eisenstadt@annafreud.org

Suzet Tanya Lereya

tanya.lereya@annafreud.org

Jessica Deighton

Jessica.DeightonPhD@annafreud.org

1 EBPU (Evidence Based Practice Unit), UCL and Anna Freud Centre, 4-8 Rodney street, London N1 9NH, UK in some populations such as children from more deprived backgrounds, or those with additional learning needs [9, 32]. Mental health disorders experienced in adolescence have a wide range of impacts and implications both within adolescence and adulthood in terms of mental health outcomes as well as other area of person's life [10]. Thus, adolescence is a key period to examine the development of mental health disorders longitudinally, particularly as during this period, young people enter puberty and experience new stressors including educational stress, sexual exploration, and peer conflict [1, 42].

Recent population surveys of adolescents also highlight that the prevalence of mental health problems and types of disorder are relatively different between genders, with adolescent girls being more prone to experience internalising disorders such as depressions or anxiety and boys being more likely to experience externalising problems [4, 20, 47]. A range of theories in psychological wellbeing and mental health outcomes in adolescence have proposed determinants 
of gender difference and their associated effects [14]. An influential theory, the Gender Intensification Hypothesis, posits that the increased pressure for girls and boys to conform to normative gender roles during adolescence with the onset of puberty explains the emergence of the gender difference in depression. Girls enter the state of pubertal development before boys and thus undergo associated physical and hormonal changes. Early pubertal development in girls along with effects of femininity has been linked to depressive systems and is considered as a factor in the gender differences of depression [7,28]. Studies also suggest that girls that mature early display increased levels of depressive symptoms than those whose pubertal timing is similar to that of their peers [21, 28, 31, 37].

Peer relationships have been also considered to be a pertinent risk factor to explain the gender differences in mental health problems. The transition from childhood to adolescence creates greater difference in the individual and social context that peer relations comes salient. Peer relations become a significant source of influence on adolescent attitude, activities, and emotional wellbeing [3]. In these circumstances, girls often display an increased level of sensitivity to distress in other peers, more empathy and fear rejection by peers than their male counterparts, [30, 41] causing significant internalizing symptoms [40].

Furthermore, research suggests that the differences in managing and coping with stressors between boys and girls can be another relevant factors. Several studies found that girls may perceive more difficulties from the same stressors and report more frequently than boys [16, 24, 44]. This can be related with the fact that boys tend to ignore problems as a strategy to cope with problems $[15,43]$ or seek distraction through physical activities [39], while girls are more willing to seek support through family, school, and/or friends [49].

\section{Objectives}

Despite evidence reporting gender difference in adolescent mental health, it remains unclear when and how the divergence between boys and girls happens. To address this issue, this study draws on a recent, large-scale longitudinal data from a community-based survey of adolescents to explore gender differences in mental health and wellbeing over time. Using these data, we aim to examine longitudinal trajectories of mental health problems and subjective wellbeing over time between boys and girls, moving from early (11-12 years old) to mid-adolescence (13-14 years old), while accounting relevant predictive factors.

\section{Methods}

\section{Study design/setting}

This study utilised survey data collected from the HeadStart programme as well as socio-demographic data extracted from the National Pupil Database (NPD). The HeadStart programme is a 6-year, $£ 67.4$ million National Lottery funded programme, aiming to improve mental health problems and wellbeing of children and young people aged 10-16 and prevent developing serious mental health issues. It is based on six local authorities in England and the programme works with local young people, schools, families, charities, communities, and public services to deliver a wide range of early interventions for young people. Every year, the children and young people who participate in the HeadStart programme complete an annual survey (The Wellbeing Measurement Framework, WMF) at their schools. The socio-demographic characteristics of children and young people were extracted through a data linkage with the NPD.

\section{Participants}

This study is based on children and young people who participated in the WMF yearly, starting in 2017, when they were in year 7 (aged 11-12) until 2019, when they were in year 9 (aged $13-14)$. Out of the 10,888 children and young people who participated in the survey yearly, 2,276 children and young people either had missing data at least one time point from the survey or had no socio-demographic data from the NPD. Hence, 8,612 pupils from 121 state secondary schools were included in the final analyses with all study variables. Of those not included in the analyses, there were relatively higher proportion of children and young people from Black ethnic background, with free school meals (FSM) eligibility, special education needs (SEN) status. Compared to the national average, the study sample had a slightly higher proportion of children and young people from deprived backgrounds based on FSM eligibility (study sample: $14.3 \%$, national average: $12.9 \%$ ). The study sample had much lower proportion of children and young people with SEN support (study sample: 9.7\%, national average: $14.4 \%$ ), slightly higher proportion of White children and young people (study sample: $76.9 \%$, national average: $75.2 \%$ ), and more females (study sample $56.0 \%$, national average: $49.3 \%$ ).

\section{Variables}

\section{Main outcomes}

Children and young people's mental health difficulties were measured with the child self-report Strengths and Difficulties 
Table 1 Sample characteristics

\begin{tabular}{lccc}
\hline Sample characteristic & Gender & & \\
& Male $(n=3799)$ & Female $(n=4832)$ & $P$ value \\
\hline Ethnicity, $N(\%)$ & & & \\
White & $2967(78.1)$ & $3671(76.0)$ & 0.036 \\
Black & $207(5.5)$ & $261(5.4)$ & \\
Mixed & $149(3.9)$ & $205(4.2)$ & \\
Asian & $366(9.6)$ & $564(11.7)$ & 0.15 \\
Any other group & $110(2.9)$ & $131(2.7)$ & $<0.001$ \\
Eligible to FSM in the last 6 years: Yes, $N(\%)$ & $1260(33.2)$ & $1532(31.7)$ & 0.63 \\
SEN status: Yes, $N(\%)$ & $523(13.8)$ & $313(6.5)$ & $<0.001$ \\
English as additional language: Yes, $N(\%)$ & $645(17.0)$ & $839(17.4)$ & $<0.001$ \\
Student Resilience survey (SRS) & & & $<0.001$ \\
Mean score: problem solving at 2016/17 (SD) & $10.98(3.2)$ & $11.34(3.2)$ & $<0.001$ \\
Mean score: goals and aspiration at 2016/17 (SD) & $8.43(1.9)$ & $8.26(1.9)$ & 0.034 \\
Mean score: empathy at 2016/17 (SD) & $7.92(1.95)$ & $8.68(1.61)$ & $<0.001$ \\
Mean score: family connection at 2016/17 (SD) & $17.79(2.6)$ & $18.16(2.5)$ & $15.56(3.7)$ \\
Mean score: school connection at 2016/17 (SD) & $15.39(3.8)$ & $55.38(10.17)$ & \\
Mean score: peer support at 2016/17 (SD) & $50.71(11.39)$ & & \\
\hline
\end{tabular}

Questionnaire (SDQ). SDQ is a 25-item measure comprising four problem scales (emotional symptoms, conduct problems, peer-relationship problems, and hyperactivity/inattention problems) and a prosocial behavior scale. This study focused on the four problem subscales of the SDQ. The total scores of each subscale were used in the analysis and higher scores indicate higher levels of difficulty.

Subjective wellbeing was measured with the 7-item child self-report Short Warwick and Edinburgh Wellbeing Scale (SWEMWBS), and total scores were used in the analyses. High scores on the SWEMWBS indicate greater positive mental wellbeing.

\section{Main exposures}

The main exposure variable was gender, collected from the WMF survey as well as the NPD, to explore any gender differences in adolescents' mental health and wellbeing trajectories. Gender variable is coded as a binary variable.

\section{Covariates}

Various potential confounders were extracted at baseline including individuals' socio-demographic characteristics and resilience factors. Ethnicity, FSM eligibility in the last 6 years, SEN status (with or without statement), and English as an additional language were derived from the NPD. Resilience factors from the Headstart survey were derived from the Student Resilience Survey [SRS; 46] which captures a range of internal and external protective characteristics. The six of the SRS subscales-(a) problem-solving, goals and aspirations and empathy as internal protective factors and (b) family connection, school connection, and peer problem as external protective factors-which have been shown to be associated with adolescents' mental health and wellbeing $[17,29]$ were selected. Higher scores on the SRS reflect greater resilience.

\section{Procedure}

Every year, children and young people in participating schools completed surveys using a secure online system during a usual school day. The online system was designed to be easy to read and child friendly. Every year, consent for participation in the research was sought from parents prior to, and from children and young people at the outset of, the survey sessions. Parental opt outs were received by post, phone, or email, and child assent was recorded via computer at the beginning of survey sessions. This research was approved by the UCL ethics committee (reference: 8097/003).

\section{Statistical analysis}

Characteristics of the sample can be found in Table 1. To examine any gender difference in the change of adolescents' mental health and subjective wellbeing trajectories over 3 year period, generalised mixed linear models (GLMM) were applied using STATA 15.

For each outcome variable (i.e., the total scores from the 4 SDQ subscales and SWEMWBS total score), four preparatory models were estimated. First model examined the crude association between change of young people's mental health difficulties and subjective wellbeing level and gender over time. In the second model, socio-demographic 
characteristics (i.e., ethnicity and eligibility of FSM in last 6 years, SEN status, and English as additional language) were included. In the third model, SRS internal protective factors including problem solving, goals and aspirations, and empathy subscales were added. In the fourth model, SRS external protective factors including family connection, school connection, and peer support subscales were added. In the final model, the interaction between time and gender was further added into the model to identify any gender differences in mental health and subjective wellbeing trajectories. The likelihood ratio test was used to compare the model fits between the models and the model fit significantly improved successively. Therefore, all variables were retained in the final model (see Table 2).

\section{Sensitivity analysis}

To investigate whether gender difference in mental health problems and subjective wellbeing trajectories were significantly different between young people from mainstream secondary schools and other types of schools (i.e., special schools, Pupil Referral Units, and Alternative provisions), sensitivity analysis was conducted with only mainstream schools.

\section{Results}

Table 1 provides information on the socio-demographic and protective characteristics at baseline, broken down by gender. There were relatively sizeable ethnic and socio-economic diversity within the sample, particularly with those from all ethnic groups other than White, making up nearly $25 \%$ of study population. The sample included a higher proportion of boys with SEN than girls $(p<0.01)$. In addition, girls had higher resilience scores except goals and aspiration subscale at baseline $(p<0.01)$.

Table 2 presents the results from the generalized linear growth models and Figs. 1 and 2 show the change in mental health and wellbeing level over time between boys and girls, highlighting the significant gender role in early adolescent's mental health and wellbeing. ${ }^{1}$ Overall, there was a general trend of increasing mental health difficulties and declining subjective wellbeing over time when accounting for school-level variations and various socio-demographic and resilience factors at the individual level. During the early (aged 11-12) to mid-adolescent (aged 13-14) period, young people were more likely to experienc emotional difficulties, behavioral difficulties, and hyperactivity/inattention

\footnotetext{
1 The change in mental health and wellbeing scores over time between boys and girls is presented in supplementary table 1 .
}

difficulties and fairly stable level of difficulties in peer relationship as they get older. Young people's subjective wellbeing has decreased notably over this period. However, it is important to note that individual's different socio-demographic characteristics, particularly, ethnicity, FSM eligibility, SEN status, and resilience factors, were closely associated with young people's mental health and wellbeing level at baseline.

Examining the results by gender, particularly the interaction effect between gender and time, revealed that the rise in mental health problems and the decline in subjective wellbeing in the period of early to mid-adolescence were largely driven by overall deterioration for girls, since boys reported a fairly stable level of difficulties over time. These results accounted for various socio-demographic and resilience factors that were known to be linked to mental health and subjective wellbeing level. More specifically, young people's various socio-demographic and resilience characteristics were closely linked to young people's emotional difficulty level at baseline. For example, young people from Black and Asian backgrounds had significantly reduced risk of experiencing emotional difficulties than White young people. Similarly, young people who had English as additional language were less likely to experience emotional difficulties than those with English as a first language. FSM eligibility in the last 6 years was closely associated with increased chance of emotional difficulties as did having SEN status. In terms of resilience factors, several internal and external factors were negatively associated with emotional difficulties. In fact, having good problem-solving skills, high goals and aspirations, good family connections, and/or peer support significantly reduced the chance of experiencing emotional difficulties. On the other hand, the young people who had high empathy were more likely to experience emotional difficulties. Accounting for these variances in the model, there was still a marked gender difference in the trend of emotional difficulties. The average emotional difficulty level for girls was already higher than boys at the age of 11-12 and continued to increase year on year. However, boys' emotional difficulties remained relatively stable over time, even decreased slightly which resulted a significant gender differences in emotional difficulties (in the presence of interaction).

Similarly, various socio-demographic and resilience factors were closely associated with young people's behavioral difficulties level. Being Black or Asian, FSM eligibility, SEN status, English as additional language, and both internal and external resilience factors were significant predictive factors. While controlling these factors, the developmental trends in behavioral difficulties were fairly different between boys and girls over time. At the time of early adolescence (aged 11-12), boys, on average, were more likely to experience behavioral difficulties than girls. However, girls' level of 


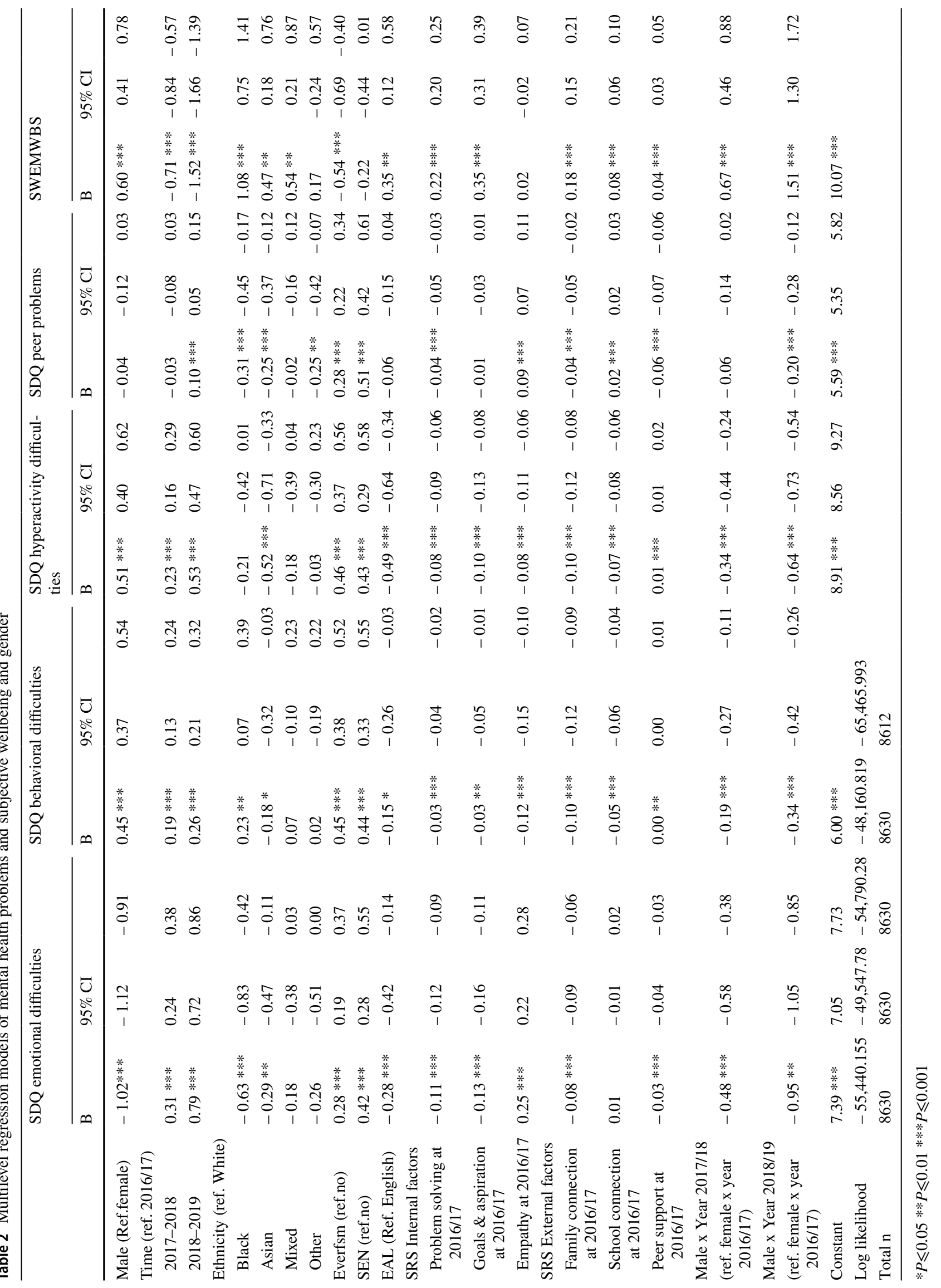




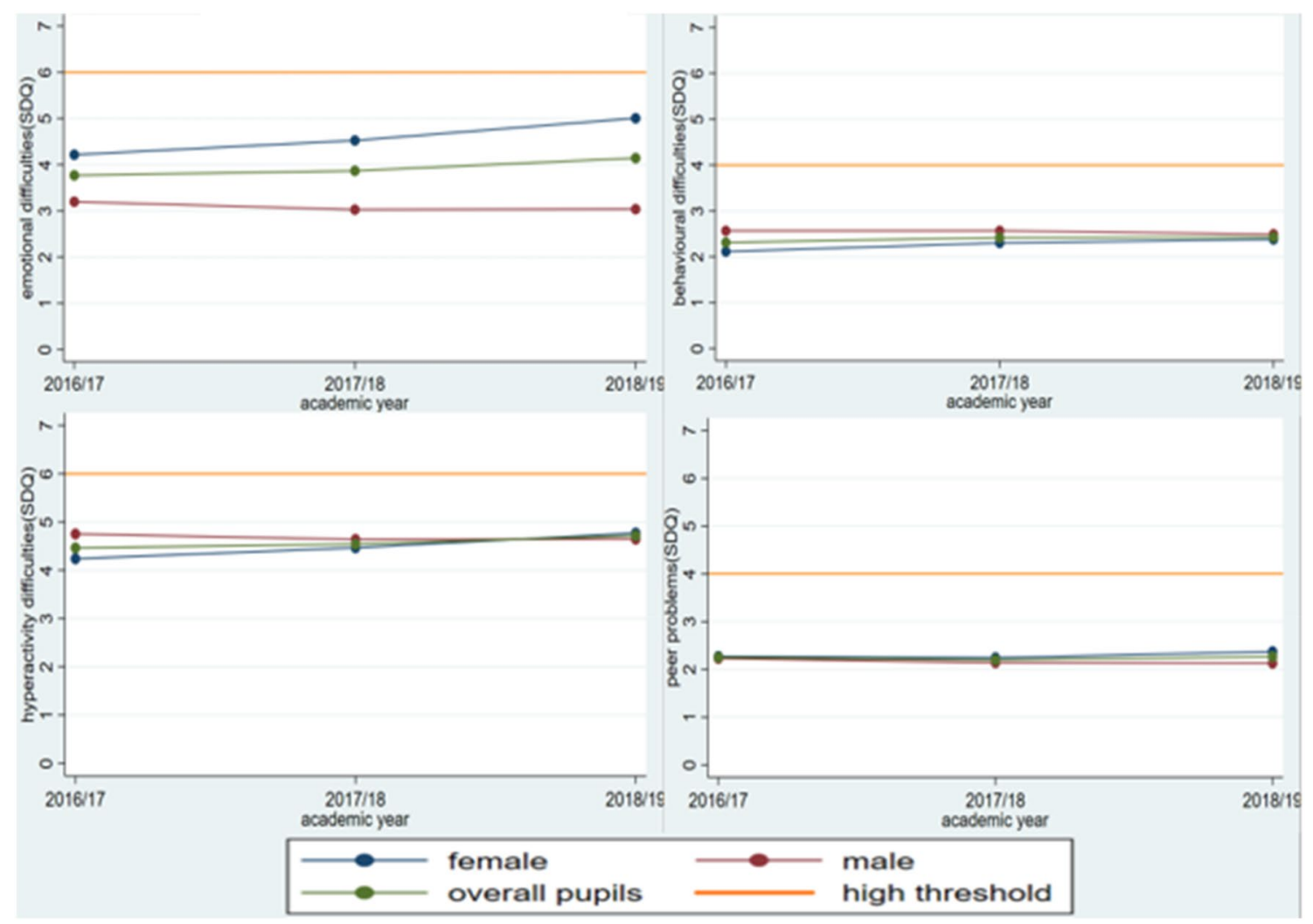

Fig. 1 Change in mental health over time

Fig. 2 Change in subjective wellbeing over time

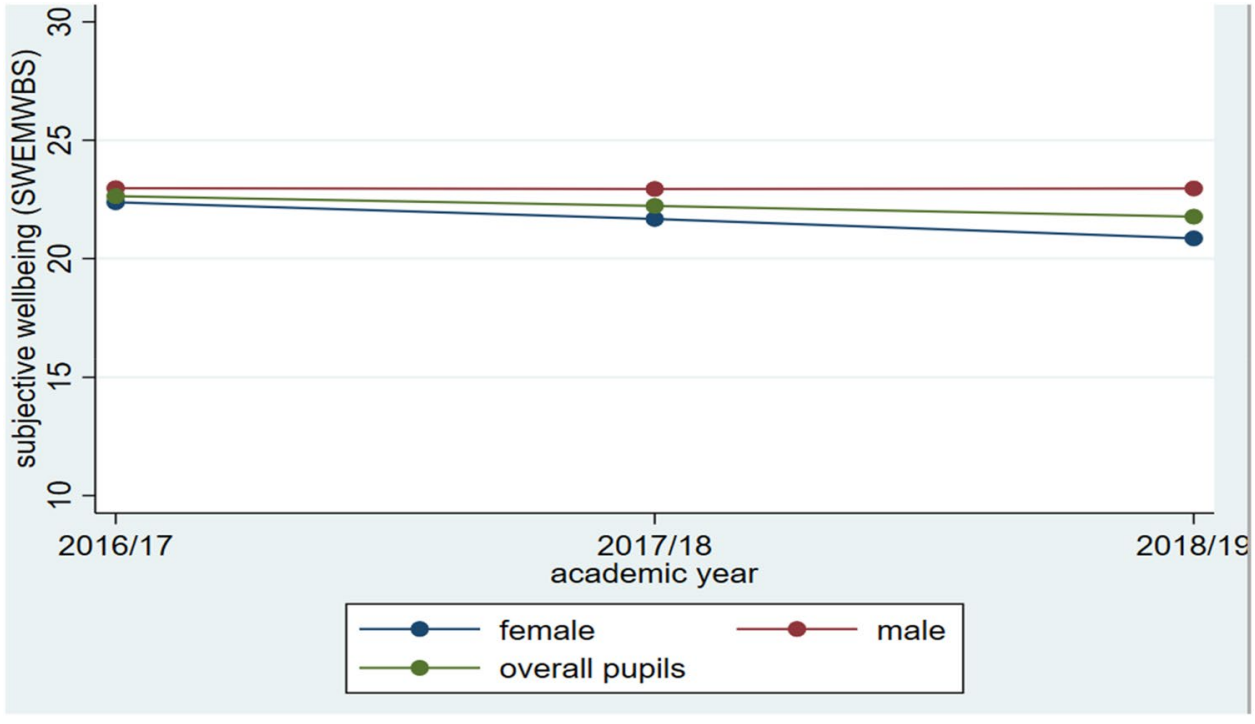

additional language and internal resilience characteristics as well as good family and school connection had significantly reduced the risk of experiencing hyperactivity/inattention difficulties. On the other hand, having SEN status and FSM eligibility were associated with nearly $50 \%$ increase in risk of experiencing hyperactivity/inattention difficulties 
respectively. By controlling these significant predictive factors, the level of hyperactivity/inattention difficulties in the early adolescent (the period of ages 11/12 to 13/14) cannot be understood without accounting for gender differences given the gender-time interaction against hyperactivity/ inattention difficulties was significant. While boys' average hyperactivity/inattention level stayed relatively stable, girls' level increased year on year.

The levels of peer-relationship problems were closely associated with a number of covariates at baseline. In particular, the young people from Black or Asian ethnic backgrounds (relative to White ethnicity), those who had good problem-solving skills, good family connections, and peer support were significantly less likely to have peer-relationship problems. By contrast, FSM eligibility, SEN status, and high empathy were closely associated with prevalence of peer-relationship problems. In terms of the peer problem scores, there were no significant differences between boys and girls at the early adolescence (age 11-12) when adjusting the impact of the covariates. However, girls were more likely to experience peer problems by the mid-adolescence than boys.

Young people's subjective wellbeing levels were closely linked to individual's various socio-economic and resilience factors as were mental health difficulties. At baseline, children and young people from Black, Asian, and mixed ethnic backgrounds (relative to White ethnicity), children and young people who identified English as additional language (relatively to first language), those who had good problem-solving skills and high goals and aspirations as well as those who had strong external supports from home, school and peers were more likely to experience better wellbeing. On the other hand, FSM eligibility had a significant inverse association with positive mental wellbeing. While these associations remained significant at baseline, the gap of subjective wellbeing levels between boys and girls had increased significantly over time. At age 11-12, girls had slightly but significantly lower subjective wellbeing than boys' and girls' wellbeing further deteriorated year on year. This indicated that there was a significant gender differences in adolescent's mental wellbeing.

In the sensitivity analyses, we did not find any significant changes in the direction or magnitude of young people's mental health problems and subjective wellbeing over time when focused on the young people and adolescents from mainstream schools (see supplementary table 2).

\section{Discussion}

In this longitudinal study of 8612 adolescent, the results showed that young people were more likely to experience a higher level of mental health problems and negative mental wellbeing as they transition through adolescence. However, it is important to note that the distress level that reported by adolescences was relatively different by gender. The overall difficulty levels that reported by girls were significantly higher than boys across a range of mental health problems and subjective wellbeing. These developmental trends persisted after controlling for a broad range of potential confounders and were robust to sensitivity analyses.

The average emotional difficulty level for girls was already higher than boys at age 11-12 and continued to increase year on year. Similarly, girls had slightly but significantly lower subjective wellbeing than boys at the age of 11-12 and their wellbeing further deteriorated year on year, while boys' wellbeing level stayed fairly stable over time. This is consistent with literature, suggesting that girls are more likely to display depressive symptoms across most of the life span, beginning at some point in adolescence [38]. It has been suggested that girls can be vulnerable to emotional problems due to earlier pubertal timing [18], negative coping styles such as rumination [36], and more problems in relationships with parents and peers [27]. In fact, the results showed that healthy family connections good peer support, having good problem-solving skills, and having goals and aspirations significantly reduced the chances of experiencing emotional difficulties which is in agreement with the existing research.[12, 25, 33, 45, 50, 51]. In addition, White young people were more likely to experience emotional difficulties and poor wellbeing than those from Black and Asian backgrounds. This is in line with the previous longitudinal findings, showing that children from ethnic minority groups have better mental health than their counterparts [19, 22]. Considering that ethnicity is a multifaceted construct which combines biological elements, ethnic self-identification, and broader social and institutional factors, it is possible that the experiences of particular groups may be shaped differently leading to more or less mental health difficulties and wellbeing [19].

Our results also showed that at the time of early adolescence (aged 11-12), boys, on average, were more likely to experience behavioral problems and hyperactivity/inattention problems compared to girls. This fits with literature suggesting that during the transition to secondary school that there is an increase in aggression and behavior difficulties in boys [13]. However, our study indicated that girls' selfreported levels of behavioral and hyperactivity/inattention problems increased to almost the same levels as boys by mid-adolescence (age 13-14). These findings demonstrated rather concerning trends for girls as the distress, they experience across a range of mental health difficulties appears higher than for boys.

While there were no significant score differences between boys and girls in early adolescence (age 11-12) in peer problem, young people with good problem-solving skills, good 
family connection, and peer support were significantly less likely to experience peer-relationship problems. This is consistent with literature, suggesting that good parental relationships and social problem-solving skills have a positive impact on how the children develop peer relationships [2, 11]. By contrast, ethnicity, FSM eligibility and SEN status were closely associated with higher prevalence of peerrelationship problems. Social acceptance research consistently shows that students with special educational needs, particularly those who are placed in mainstream schools, are accepted to a lesser degree than their non-SEN classmates [26]. This confirms that significant efforts should be invested in supporting those with additional leaning needs.

\section{Limitations and future directions}

It is important to note the limitations of the study. First, the population of the study was not drawn to be representative of all school children in England; however, the participants were from six local areas of England which increased the generalisability of the results. Second, even though selfreport is an acknowledged way of measuring adolescent mental health, it can be subject to issues including social desirability and there is generally low to modest agreement between different reporters of child mental health problems [6]. This is particularly true for boys that they tend to have difficulty articulating mental health problems which may, to some extent, a reason to explain the lower rates of difficulties reported by boys in this study $[5,48]$. Thus, qualitative work could further investigate gender differences in mental health difficulties which can help to understand the mechanisms underpinning the findings of the current study. Furthermore, a 3-year longitudinal study might not be long enough to capture the adolescents' mental health and wellbeing trajectories. Thus, future research may benefit from further time points over longer term period. Finally, the longitudinal association between the covariates, such as internal and external protective factors and mental health problems, was out of this paper's scope. The covariates were measured at the first time point; hence, the longitudinal causality cannot be established. Future studies should investigate the directionality of such relationships.

Notwithstanding these limitations, the current paper shows that boys' and girls' emotional difficulties diverge significantly from early to mid-adolescence and that girls' behavioral problems escalate in the same period. Findings suggest that early adolescence as a key period for prevention activity to reduce escalation in mental problems for girls, especially those from poorer backgrounds or those with special educational needs. Results also highlighted the importance of supportive relationships in this period, especially those who have difficulties with peers and family.
Supplementary Information The online version contains supplementary material available at https://doi.org/10.1007/s00787-022-01961-4.

Authors' contributions YY: conceptualisation, formal analysis, and writing — original draft preparation. ME: writing — original draft preparation. STL: writing — original draft preparation, writing — reviewing and editing, and verifying the underlying data. JD: conceptualisation, writing-reviewing and editing, verifying the underlying data, and funding acquisition.

Funding The data used in this study were collected as part of HeadStart learning programme and supported by funding from The National Lottery Community Fund. The content is solely the responsibility of the authors and it does not reflect the views of The National Lottery Community Fund. Jessica Deighton and Suzet Tanya Lereya is (in part) supported by the National Institute for Health Research (NIHR) Children and Families Policy Research Unit. The views expressed are those of the author(s) and not necessarily those of the NIHR or the Department of Health and Social Care.

Availability of data and materials The Headstart data used in this study were collected as part of HeadStart project, funded by the National Lottery Community Fund. The data are available from EBPU (Evidence Based Practice Unit), UCL and Anna Freud Centre and NPD (National Pupil Database is available from Department of Education, UK. Restrictions apply to the availability of these data, which were used under license for the current study and so are not publicly available.

\section{Declarations}

Conflict of interest None exist.

Ethics approval This research was approved by the UCL ethics committee (reference: 8097/003).

Consent to participate All the HeadStart survey participants provided a written informed consent.

Consent for publication N/A.

\section{References}

1. Berg MT, Simons RL, Barr A, Beach SR, Philibert RA (2017) Childhood/Adolescent stressors and allostatic load in adulthood: Support for a calibration model. Soc Sci Med 193:130-139

2. Brown BB, Bakken JP (2011) Parenting and peer relationships: reinvigorating research on family-peer linkages in adolescence. J Res Adolesc 21:153-165

3. Brown BB, Larson J (2009) Peer relationships in adolescence. In: Handbook of Adolescent Psychology

4. Campbell O, Bann D, Patalay P (2021) The gender gap in adolescent mental health: a cross-national investigation of 566,829 adolescents across 73 countries. SSM-Population Health: 100742

5. Chandra A, Minkovitz CS (2006) Stigma starts early: gender differences in teen willingness to use mental health services. J Adolesc Health 38:754.e751-758

6. Cheng S, Keyes KM, Bitfoi A, Carta MG, Koç C, Goelitz D, Otten R, Lesinskiene S, Mihova Z, Pez O, Kovess-Masfety V (2018) Understanding parent-teacher agreement of the Strengths and Difficulties Questionnaire (SDQ): Comparison across seven European countries. Int J Methods Psychiatr Res 27 
7. Conley CS, Rudolph KD (2009) The emerging sex difference in adolescent depression: Interacting contributions of puberty and peer stress. Dev Psychopathol 21:593

8. Deighton J, Humphrey N, Belsky J, Boehnke J, Vostanis P, Patalay P (2018) Longitudinal pathways between mental health difficulties and academic performance during middle childhood and early adolescence. Br J Dev Psychol 36:110-126

9. Deighton J, Lereya ST, Casey P, Patalay P, Humphrey N, Wolpert M (2019) Prevalence of mental health problems in schools: poverty and other risk factors among 28000 adolescents in England. Br J Psychiatry 215:565-567

10. Department of Health (2014) Wellbeing and health policy. Wellbeing and why it matters to health. In: Health Do (ed)

11. Dubow EF, Tisak J, Causey D, Hryshko A, Reid G (1991) A twoyear longitudinal study of stressful life events, social support, and social problem-solving skills: contributions to children's behavioral and academic adjustment. Child Dev 62:583-599

12. Eames V, Shippen C, Sharp H (2016) The team of life: a narrative approach to building resilience in UK school children. Educ Child Psychol 33:57-68

13. Espelage DL, Bosworth K, Simon TR (2001) Short-term stability and prospective correlates of bullying in middle-school students: an examination of potential demographic, psychosocial, and environmental influences. Violence Vict 16:411-426

14. Esteban-Gonzalo S, Esteban-Gonzalo L, Cabanas-Sánchez V, Miret M, Veiga OL (2020) The investigation of gender differences in subjective wellbeing in children and adolescents: the UP\&DOWN study. Int J Environ Res Public Health 17:2732

15. Frydenberg E (2008) Adolescent coping: Advances in theory, research and practice. Routledge

16. Frydenberg E (1997) Adolescent coping: theoretical and research perspectives. Psychology Press

17. Garmezy N (1985) Stress-resistant children: the search for protective factors. Recent Res Dev Psychopathol 4:213-233

18. Ge X, Conger RD, Elder GH Jr (2001) Pubertal transition, stressful life events, and the emergence of gender differences in adolescent depressive symptoms. Dev Psychol 37:404-417

19. Goodman A, Patel V, Leon DA (2008) Child mental health differences amongst ethnic groups in Britain: a systematic review. BMC Public Health 8:1-11

20. Green H, McGinnity Á, Meltzer H, Ford T, Goodman R (2005) Mental health of children and young people in Great Britain, 2004. Palgrave Macmillan Basingstoke

21. Hamlat EJ, Snyder HR, Young JF, Hankin BL (2019) Pubertal timing as a transdiagnostic risk for psychopathology in youth. Clin Psychol Sci 7:411-429

22. Harding S, Whitrow M, Maynard MJ, Teyhan A (2007) Cohort profile: The DASH (Determinants of Adolescent Social wellbeing and Health) Study, an ethnically diverse cohort. Int J Epidemiol 36:512-517

23. Hastings PD, Zahn-Waxler C, Robinson J, Usher B, Bridges D (2000) The development of concern for others in children with behavior problems. Dev Psychol 36:531-546

24. Jose PE, Ratcliffe V (2004) Stressor frequency and perceived intensity as predictors of internalizing symptoms: gender and age differences in adolescence. N Z J Psychol 33:145-154

25. Keskin G, Cam O (2010) Adolescents' strengths and difficulties: approach to attachment styles. J Psychiatr Ment Health Nurs 17:433-441

26. Koster M, Pijl SJ, Ev H, Nakken H (2007) The social position and development of pupils with SEN in mainstream Dutch primary schools. Eur J Spec Needs Educ 22:31-46

27. Leadbeater BJ, Kuperminc GP, Blatt SJ, Hertzog C (1999) A multivariate model of gender differences in adolescents' internalizing and externalizing problems. Dev Psychol 35:1268-1282
28. Lewis G, Ioannidis K, van Harmelen A-L, Neufeld S, Stochl J, Lewis G, Jones PB, Goodyer I (2018) The association between pubertal status and depressive symptoms and diagnoses in adolescent females: a population-based cohort study. PLoS One 13:e0198804

29. Luthar S (2006) Resilience in development: a synthesis of research across five decades. In: Risk, disorder, and adaptation. Wiley, p 739-795

30. McDonald KL, Bowker JC, Rubin KH, Laursen B, Duchene MS (2010) Interactions between rejection sensitivity and supportive relationships in the prediction of adolescents' internalizing difficulties. J Youth Adolesc 39:563-574

31. Mendle J, Ryan RM, McKone KM (2018) Age at menarche, depression, and antisocial behavior in adulthood. Pediatrics 141

32. Merikangas KR, Avenevoli S, Costello EJ, Koretz D, Kessler RC (2009) National comorbidity survey replication adolescent supplement (NCS-A): I. Background and measures. J Am Acad Child Adolesc Psychiatry 48:367-379

33. Moore GF, Cox R, Evans RE, Hallingberg B, Hawkins J, Littlecott HJ, Long SJ, Murphy S (2018) School, peer and family relationships and adolescent substance use, subjective wellbeing and mental health symptoms in wales: a cross sectional study. Child Indic Res 11:1951-1965

34. NHS Digital (2018) Mental health of children and young people in England, 2017. In, London

35. NHS Digital (2020) Mental Health of Children and Young People in England, 2020: Wave 1 follow up to the 2017 survey. In:NHS Digital

36. Nolen-Hoeksema S, Girgus JS (1994) The emergence of gender differences in depression during adolescence. Psychol Bull 115:424-443

37. Patton GC, Olsson C, Bond L, Toumbourou JW, Carlin JB, Hemphill SA, Catalano RF (2008) Predicting female depression across puberty: a two-nation longitudinal study. J Am Acad Child Adolesc Psychiatry 47:1424-1432

38. Piccinelli M, Wilkinson G (2000) Gender differences in depression: critical review. Br J Psychiatry 177:486-492

39. Plenty S, Östberg V, Almquist YB, Augustine L, Modin B (2014) Psychosocial working conditions: an analysis of emotional symptoms and conduct problems amongst adolescent students. J Adolesc 37:407-417

40. Purdie V, Downey G (2000) Rejection sensitivity and adolescent girls' vulnerability to relationship-centered difficulties. Child Maltreat 5:338-349

41. Rose AJ, Rudolph KD (2006) A review of sex differences in peer relationship processes: potential trade-offs for the emotional and behavioral development of girls and boys. Psychol Bull 132:98

42. Schaffhuser K, Allemand M, Schwarz B (2017) The development of self-representations during the transition to early adolescence: The role of gender, puberty, and school transition. J Early Adolesc 37:774-804

43. Seiffge-Krenke I (2013) Stress, coping, and relationships in adolescence. Psychology Press

44. Seiffge-Krenke I, Aunola K, Nurmi JE (2009) Changes in stress perception and coping during adolescence: the role of situational and personal factors. Child Dev 80:259-279

45. Spence SH, Sheffield J, Donovan C (2002) Problem-solving orientation and attributional style: moderators of the impact of negative life events on the development of depressive symptoms in adolescence? J Clin Child Adolesc Psychol 31:219-229

46. Sun J, Stewart D (2007) Development of population-based resilience measures in the primary school setting. Health Educ 107:575-599

47. Van Droogenbroeck F, Spruyt B, Keppens G (2018) Gender differences in mental health problems among adolescents and the 
role of social support: results from the Belgian health interview surveys 2008 and 2013. BMC Psychiatry 18:1-9

48. Vogel DL, Heimerdinger-Edwards SR, Hammer JH, Hubbard A (2011) "Boys don't cry": examination of the links between endorsement of masculine norms, self-stigma, and help-seeking attitudes for men from diverse backgrounds. J Couns Psychol 58:368-382

49. Wilhsson M, Svedberg P, Högdin S, Nygren JM (2017) Strategies of adolescent girls and boys for coping with school-related stress. J Sch Nurs 33:374-382
50. Wille N, Bettge S, Ravens-Sieberer U (2008) Risk and protective factors for children's and adolescents' mental health: results of the BELLA study. Eur Child Adolesc Psychiatry 17(Suppl 1):133-147

51. Zimmer-Gembeck MJ, Skinner EA The Development of Coping: Implications for Psychopathology and Resilience. In: Developmental Psychopathology, p 1-61 